\title{
Multi-scale characterization of material and surface integrity of Inconel 718 when milling by Abrasive Water Jet process: Context of repair application
}

Lorena Cano Salinas, Kamel Moussaoui, Akshay Hejjaji, Mehdi Salem, Anis Hor and Redouane Zitoune

Lorena Cano Salinas. Institut Clément Ader, CNRS UMR 5312, 3 Rue Caroline Aigle, 31400 Toulouse, France

Corresponding author: Lorena Cano Salinas. E-mail address: lorena.cano-salinas@univ-tlse3.fr

Kamel Moussaoui. Institut Clément Ader, CNRS UMR 5312, 3 Rue Caroline Aigle, 31400 Toulouse, France

Akshay Hejjaji. Institut Clément Ader, CNRS UMR 5312, 3 Rue Caroline Aigle, 31400 Toulouse, France

Mehdi Salem. Institut Clément Ader, CNRS UMR 5312, Campus Jarlard, 81013 Albi, France

Anis Hor. Institut Clément Ader, CNRS UMR 5312, 3 Rue Caroline Aigle, 31400 Toulouse, France

Redouane Zitoune. Institut Clément Ader, CNRS UMR 5312, 3 Rue Caroline Aigle, 31400 Toulouse, France

\begin{abstract}
Inconel 718 (IN718) is a precipitation hardened nickel-base super-alloy exhibiting poor machinability and used in the hot section of aircraft engines. These components are subjected to severe thermo-mechanical loads in a highly corrosive environment, limiting their service life due to cracks and wear. Due to their high added-value, repair of damaged IN718 components is an interesting alternative instead their replacement. Repair process involves material removal of the damaged zone and subsequent cavity refill. Nevertheless, material removal of IN718 by conventional methods is a challenging task. Abrasive Water Jet (AWJ), a nonconventional machining process, offers a potential alternative to mitigate IN718 machining problems. However, research on the impact of AWJ process parameters during IN718 milling on the surface and material integrity is limited in the literature. Furthermore, in repair context, no study proposes AWJ machining as material removal process. The present work focuses on a multi-scale characterization of the influence of AWJ process parameters (pressure, traverse speed, step-over distance and abrasive size) on surface roughness, depth of cut, abrasive embedment and residual stress, during milling of untreated IN718. Surface integrity characterization on the milled surfaces was conducted through 3D optical microscopy, profilometry and SEM techniques. Residual stress measurements were performed in longitudinal and transverse directions with respect to the machining path using XRD technique. The results showed that all milled surfaces presented abrasive embedment and a compressive residual stress state with similar values in both directions. Up to $15 \%$ of the area of a milled surface consisted of abrasive embedment. The tool path has not influenced the residual stresses. Furthermore, surface roughness is dependent on pressure and traverse speed; depth of cut is influenced by pressure, traverse speed and grit size; abrasive embedment depends on pressure, step-over distance and grit size; whilst, residual stresses are influenced by traverse speed and grit size.
\end{abstract}

Keywords. AWJ, Inconel 718, Roughness, Abrasive Embedment, Depth Of Cut, Residual Stresses, Grit Size

\section{Introduction}

Inconel 718 (IN718) is a precipitation hardened nickel-based super-alloy widely used for aircraft engines (turbine blades, vanes, blisks) that are subjected to severe thermo-mechanical loads in a highly corrosive environment. These harsh conditions can limit the service life of IN718 components due to cracks and wear [1]. Therefore, repair of damaged IN718 components is an interesting alternative instead of replacing these high added-value parts $[1,2]$. In repair context, the material removal of the impaired area is the first step of the process followed by cavity refill [1-6]. Nevertheless, conventional material removal methods is a well-known challenging task for IN718, since nickelbased super-alloys are classified as "difficult-to-machine" materials. The most important properties of IN718 are good strength at high temperatures, good corrosion resistance and high hardness [7]. The retention of its properties during machining combined with its poor thermal conductivity makes Inconel 718 difficult-to-machine material by conventional machining processes [8]. 
Multi-scale characterization of material and surface integrity of Inconel 718 when mill...

Abrasive Water Jet Machining (AWJM) is a non-conventional machining process where a mixture of high-pressure water with abrasive grit particles is forced to pass through a nozzle and converted to a high-velocity jet focused to erode a desired material. AWJ for milling application appeared decades ago for difficult-to-cut materials by conventional machining processes $[9,10]$. The main advantages of AWJ process are a negligible heat affected zone on the target piece and the potential to cut very hard materials, such as titanium or Inconel [11].

The literature review in conventional machining of IN718 reports excessive and rapid tool wear due to the mechanical and thermal loads. A poor surface quality is reported as a result of chips to weld to cutting edges known as built-up edges (BUE) and the presence of hard abrasive carbide particles on cutting tool $[12,13]$. Moreover, studies report an alteration in the microstructure of IN718 in form of plastic deformation or recrystallization with grain refinement and changes in morphology and orientation of the grain [12, 14-17]. With regard to mechanical changes, a tensile residual stress state at the surface which then shifts to compressive residual state beneath the surface is reported [12, $14,16,18]$.

AWJ process provides a potential alternative to mitigate difficulty in machining of IN718. AWJ is characterized by a large number of process parameters [19], the most influential in terms of machined surface characteristics are jet pressure, traverse speed, stand-off distance and abrasive flow rate [11]. However, the main issue of AWJ process is the presence of abrasive particles impregnated during machining.

The literature available on the influence of AWJ parameters in the machined surface of IN718 is limited. Bhandarkar et al. [20] focuses on characterizing pockets milled by AWJ in order to optimize process parameters for pocket dimensions and surface roughness. They found that the surface roughness decreases at lower pressure and at higher traverse speed, whereas for pocket depth, higher pressure with lower traverse speed is preferred. Holmberg et al. [14] examined alloy 718 milled surfaces by Electron Discharge Machining (EDM), laser and AWJ and compared them with conventional milling in terms of surface integrity using one setting for each machining. They concluded that the AWJ machining condition produced highly desirable surface with low surface roughness and high compressive residual stress on the surface. Escobar-Palafox et al. [21] investigated pocket milling in terms of geometry and depth of cut when using different process parameters. They showed that the pressure is the main parameter influencing the depth of cut. However, the pressure had a non-linear behavior. Further, they reported that lower traverse speed with higher abrasive flow rate are required to achieve deeper depth of cut. Ay et al. [22] investigated the effect of traverse speed on kerf shape in jet singles passes and concluded that lower traverse speed generates deeper depth of cut and wider kerf as a result of the exposure time leading to more overlapping area. Rivero et al. [23] analyzed milled surfaces with different setting process parameters and reported that abrasive flow rate, pressure and stand-off distance have a significant influence on surface roughness. It was noticed an increase in roughness with an increase in pressure; whilst surface roughness decreases with increasing abrasive flow rate. They also analyzed abrasive embedment and reported an increase when increasing the pressure, the traverse speed and the stand-off distance. Patel et al. [24] analyzed abrasive embedment in aluminum alloy comparing straight cutting and oscillation cutting and found that, for ductile materials, oscillation cutting is 10 times better than straight cutting with respect to abrasive embedment. They also reported a reduction of the particles contamination when increasing the depth of cut. Fowler et al. [25] examined titanium alloy milled surfaces and showed that abrasive size has only a small influence on the level of abrasive embedment. Boud et al. [26] investigated embedment particles in kerf cutting of titanium alloy with five different types of \#80 garnet abrasive and concluded that despite the morphology and hardness of the abrasive, there was no significant difference in the abrasive embedment. Shipway et al. [27] analyzed two different abrasive sizes with different jet impingement angles and observed overall that abrasive embedment increased with the increase in the impingement angle.

These previous studies of AWJ milling of IN718 revealed that lower pressures and higher speeds improve surface roughness [20,22,23] whilst depth of cut increase at higher pressures and lower traverse speed [20-22]. Further, in all AWJ machined surfaces was reported the presence of embedded abrasive particles [14, 22-27]. However, a quantitative 
evaluation could not made due to the different settings for machining used from the previous investigations.

Researchers have not performed a study with a wide range of process parameters and their effects on surface characteristics in IN718 as on date. The present work analyzes the influence of the AWJ milling process (viz. jet pressure, traverse speed and stepover distance) on the machined surface of Inconel 718, in terms of surface roughness, depth of cut, degree of embedded abrasive particles and surface residual stresses. In addition, two different abrasive sizes are compared varying the pressure in terms of characteristics surface.

\section{Experimental procedure}

The material used is annealed Inconel alloy 718. A full factorial experimental design including three machining parameters (viz. water jet pressure, traverse speed and scan step) at three levels was performed on Inconel 718 specimens resulting in twenty-seven combinations using abrasive garnet mesh \#120. All tests were carried out in an Abrasive Water Jet Machine Flow MACH4-C while keeping the stand-off distance and the abrasive flow rate constant. The orifice diameter, the focusing tube and the nozzle diameter sizes used are $0.33 \mathrm{~mm}, 1.016 \mathrm{~mm}$ and $76 \mathrm{~mm}$ respectively. In addition, in order to analyze the effect of the abrasive size, the pressure was varied at other two levels with abrasive garnet mesh \#80. The process parameters used to perform the milling are stated in the Table 1. Samples were prepared in $180 \mathrm{~mm} \times 20 \mathrm{~mm} \times 3.71 \mathrm{~mm}$ dimensions. Each test sample was milled at the same set machining parameters in order to create four blind pockets of $20 \mathrm{~mm}$ of length (Fig. 1b) following a raster scan tool path and keeping jet direction changes outside the workpiece to avoid acceleration and deceleration effects of the jet (Fig. 1a).

(a)
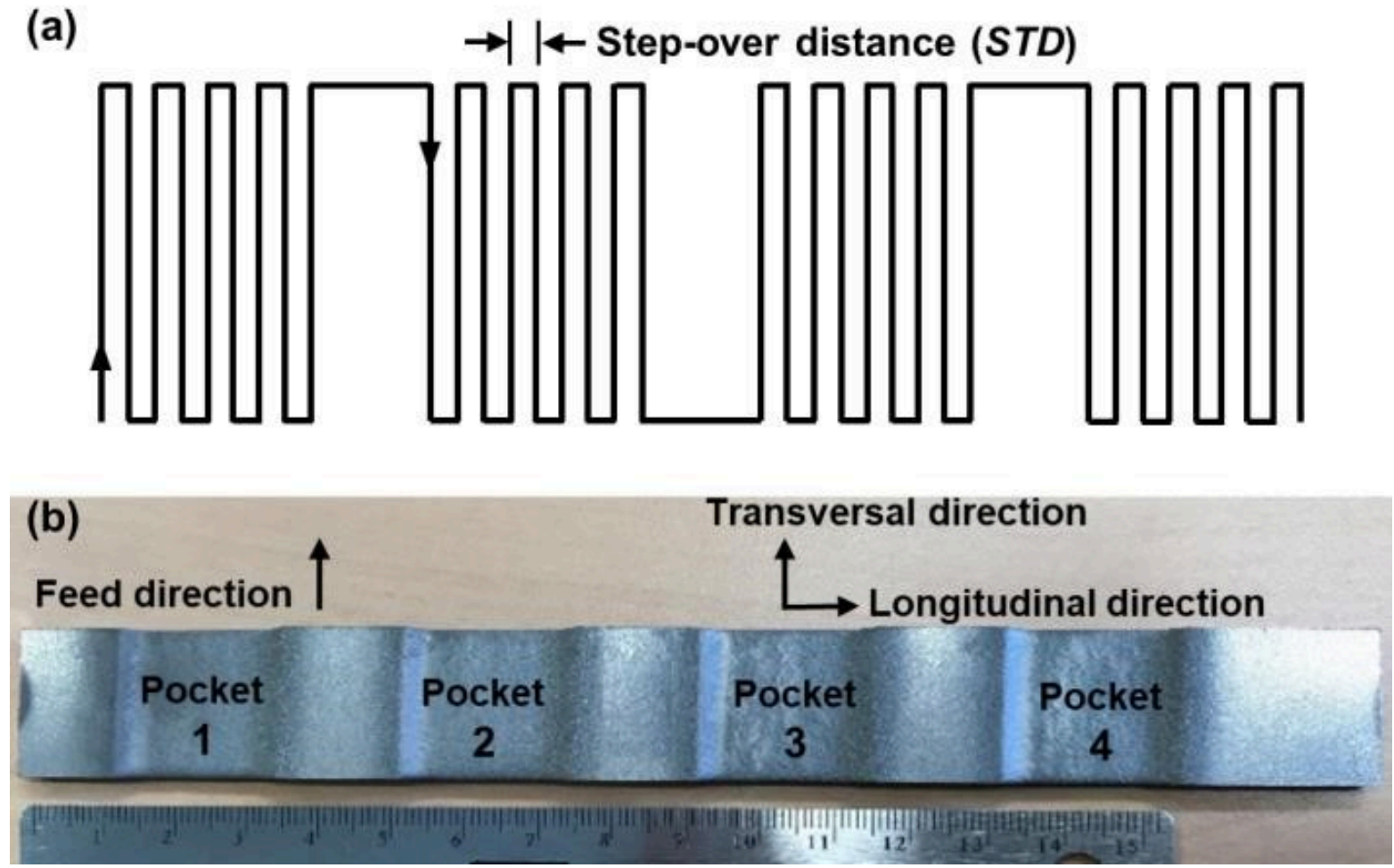

Fig. 1. (a) Tool path; (b) Sample machined at $P=250 M P a, f=1 \mathrm{~m} / \mathrm{min}$ and $S T D=0.5 \mathrm{~mm}$.

The milled surfaces were characterized in terms of surface roughness, pocket depth, embedded abrasive particles area and residual stress. The roughness measurements of all pockets were performed using an Alicona Infinite Focus 3D optical profilometer over a surface area of $5.7 \mathrm{~mm} \times 5.7 \mathrm{~mm}$ at the center of each machined pocket with a vertical and 
Multi-scale characterization of material and surface integrity of Inconel 718 when mill...

lateral resolution of $0.10 \mu \mathrm{m}$ and $4.00 \mu \mathrm{m}$ respectively. No filter was applied for treating the 3D data set.

The depth of cut of each machined pocket was measured using an Altisurf ${ }^{(\subseteq)} 520 \mathrm{v}$ microscope by scanning a profile of $40 \mathrm{~mm} \times 2 \mathrm{~mm}$ along each pocket using vertical resolution of $0.50 \mu \mathrm{m}$ and a lateral resolution of $10.00 \mu \mathrm{m}$. The measured data was filtered using a Gaussian filter to remove the outliers.

Residual stress measurements were performed by means of X-ray diffraction (XRD) technique. Residual stresses were evaluated on the middle of the machined pocket along parallel $\left(\sigma_{11}\right)$ and perpendicular $\left(\sigma_{22}\right)$ directions respect to the feed. The XRD measurements were performed using 6-axis XRayBot ${ }^{\circledR}$ apparatus equipped with a goniometer with a pure $S i$ solid detector and $M n$ radiation source $\left(\mathrm{Mn}-\mathrm{K} \alpha 1, \lambda=2.10 \mathrm{~A}^{\circ}\right)$. The lattice plane $\{311\}$ of the nickel austenitic phase (fcc) was measured at $2 \theta$ diffraction peak located at $150^{\circ}$. The X-ray was generated with $20 \mathrm{kV}$ of tension and a current of $1 \mathrm{~mA}$. The spot was passed through a circular hole of $5 \mathrm{~mm}$ in diameter without collimator, and the $\mathrm{Mn}-\mathrm{K} \beta \lambda=1.91 \mathrm{~A}^{\circ}$ was removed using a chrome filter. The three-dimensional scans involved 38 positions with 19 tilt angles $\left(-38^{\circ}<\Psi<40^{\circ}\right)$ and 2 rotation angles $\left(\varphi=0^{\circ}\right.$ for $\sigma_{11}$ and $\varphi=90^{\circ}$ for $\left.\sigma_{22}\right)$. The Xrays were recorded at each position for an angular range between $136^{\circ}<2 \theta<168^{\circ}$. Time exposition was fixed at $120 \mathrm{~s}$ for each position. Residual stresses data were computed by StressDiff ${ }^{\circledR}$ software based on the conventional $\sin ^{2}(\Psi)$ method using the X-ray elastic constants of the Inconel 718.

In order to quantify the surface fraction of residual abrasive and organic particles induced by machining, the microstructures of the outer surface were examined by means of backscattered electrons (BSE) method using Nova NanoSEM 450 (FEI) scanning electron microscope. The microanalysis was conducted over a surface of $850 \times 734 \mu \mathrm{m}$ in nine different positions of the milled pocket. The images were analyzed by means of the software ImageJ using a Gaussian blur filter in order to reduce image noise; then applying a suitable threshold to identify the boundaries of the abrasive particles.

Table 1. AWJ process parameters.

\begin{tabular}{llll}
\hline Fixed parameters & \multicolumn{3}{l}{ Variable parameters } \\
\hline Parameter & Setting & Parameter & Levels \\
\hline Stand-off distance $(\mathrm{mm})$ & 100 & Pressure, $P(\mathrm{MPa})$ & $200,250,300$ \\
Abrasive flow rate $(\mathrm{kg} / \mathrm{min})$ & 0.18 & Traverse speed, $f(\mathrm{~m} / \mathrm{min})$ & $0.5,1,1.5$ \\
Abrasive grit size & $\# 120$ & Step-over distance, STD $(\mathrm{mm})$ & $0.5,1,1.5$ \\
\hline Stand-off distance $(\mathrm{mm})$ & 100 & Pressure $(\mathrm{MPa})$ & 250,300 \\
Abrasive flow rate $(\mathrm{kg} / \mathrm{min})$ & 0.18 & & \\
Abrasive grit size & $\# 80$ & & \\
Step-over distance $(\mathrm{mm})$ & 0.5 & & \\
Traverse speed $(\mathrm{m} / \mathrm{min})$ & 1 & & \\
\hline
\end{tabular}

\section{Results and discussion}

The results of pocket depth, roughness and residual stress is the average value obtained from the four pockets measurements made with same machining parameters. The percentage of embedded abrasive particles was calculated of the average of the nine measures made on the pocket 3 of each specimen. 


\subsection{Roughness}

In order to evaluate surface roughness, the arithmetical mean height $(\mathrm{Sa})$ was used. The average roughness values varies from 12 to $25 \mu \mathrm{m}$. All AWJ milled surfaces show relatively high roughness compared to roughness values obtained when machining by conventional process $[12,14]$.

Fig. 2 depicts the effect of the traverse speed on the surface roughness when varying the pressure. The results show that an increase in pressure generates an increase in surface roughness. This is due to the fact that, at higher pressures, the abrasive particles possess higher kinetic energy which produces deeper indentations when impacting in the target material and consequently creating rougher surfaces. The same effect was reported by Rivero et al. [23] when milling alloy 718 by AWJ at different machining conditions. On the other hand, when traverse speed increases, the surface roughness decreases overall (Fig. 2). For the conditions studied by Fowler et al. [28], in titanium alloys with jet single passes, it was found an increase in roughness $(R a)$, when increasing traverse speed. They concluded that there is a ratio between the abrasive hardness and the target material that influences the surface roughness. Gupta et al. [11] found that surface roughness $(R a)$ was impacted by the abrasive flow rate when milling pockets in SS304 material.

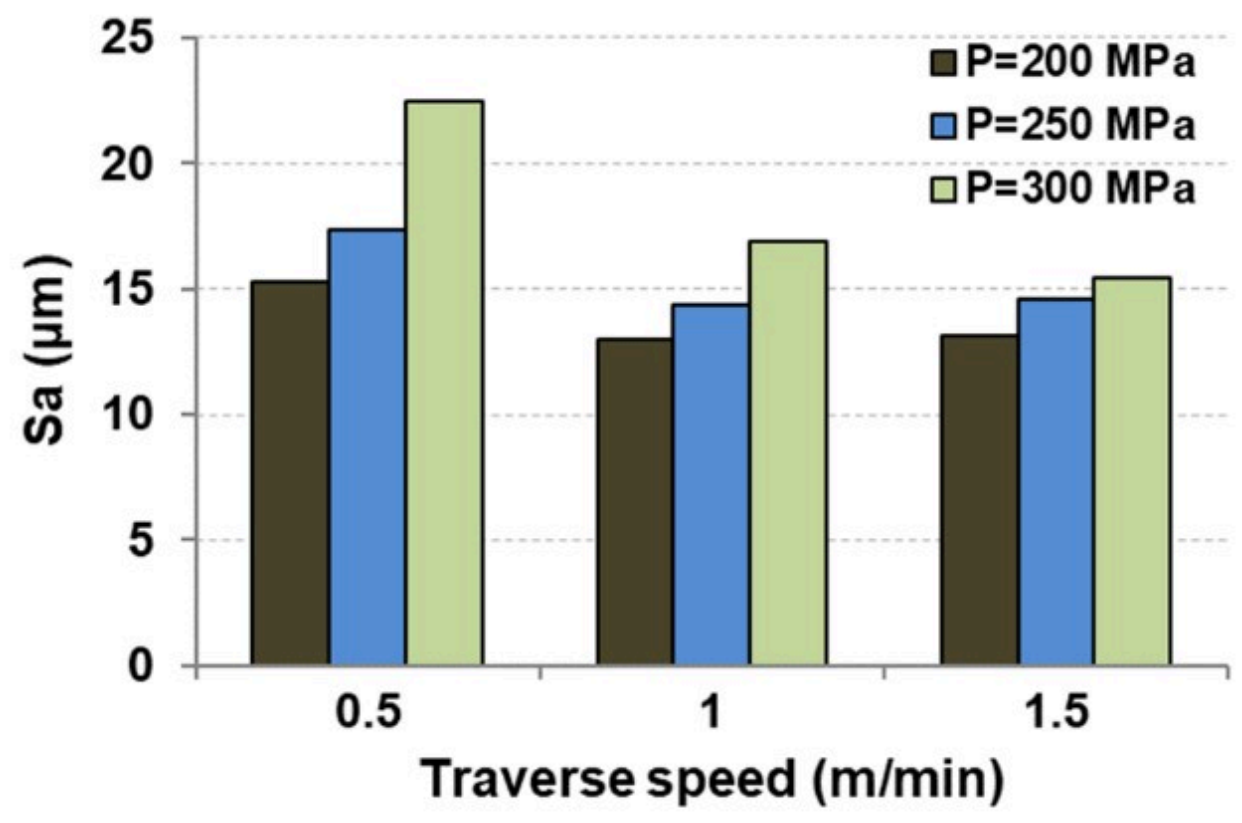

Fig. 2. Effect of pressure and traverse speed on surface roughness.

\subsection{Embedded abrasive particles}

All AWJ milled surfaces presented abrasive embedment (Fig. 3a) where contamination area varies between $7 \%$ and $14 \%$. Fig. $3 \mathrm{~b}$ shows that the degree of abrasive embedment decreases with the increase in pressure and when decreasing step-over distance. These effects can be explained by considering that higher pressures can break the embedded abrasive particles into smaller particles or remove embedded abrasive particles from precedent passes. Similarly, smaller step-over distances generate greater overlapped area on the surface, which can remove abrasive particles from precedent passes. In the conditions performed by Rivero et al. [23] in alloy 718 was observed that, when increasing the pressure and the traverse speed, the abrasive embedment also increased. 
a)

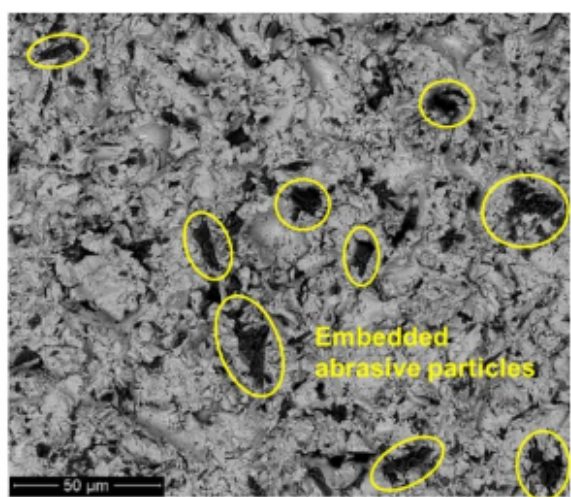

b)

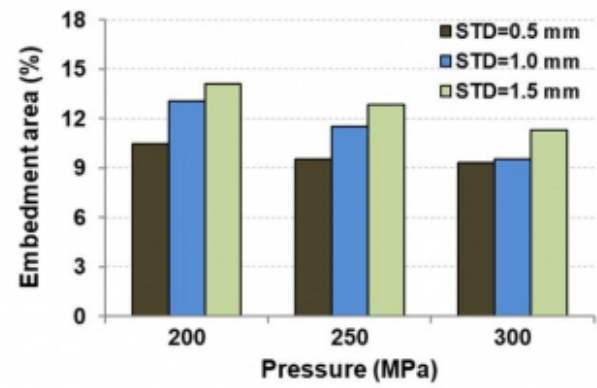

Fig. 3. (a) SEM micrograph of third pocket of the specimen milled at $P=250 \mathrm{MPa}, f=1.5 \mathrm{~m} / \mathrm{min}$ and $S T D=1 \mathrm{~mm}$; (b) Percentage of abrasive embedment area in function of the jet pressure and step-over distance.

\subsection{Depth of cut}

The obtained average pocket depths varies from 0.26 to $2.53 \mathrm{~mm}$. It can be observed in Fig. 4 that when increasing the pressure, the pocket depth also increases. The same effect was reported in [20]. In [21] was showed that depth of cut is strongly influenced by the pressure. This is due to the kinetic energy of the abrasive particles, at higher pressures, high energy transfer occurs between the abrasive particle and the target material, leading to more material removal. On the other hand, the pocket depth decreases with the increase in traverse speed (Fig. 4). This is due to the exposure time of the waterjet with the target material, at higher traverse speeds less time is needed for milling leading to lower pocket depth. In $[11,20,22]$ were also reported to occur the same trend in IN718 and stainless steel.

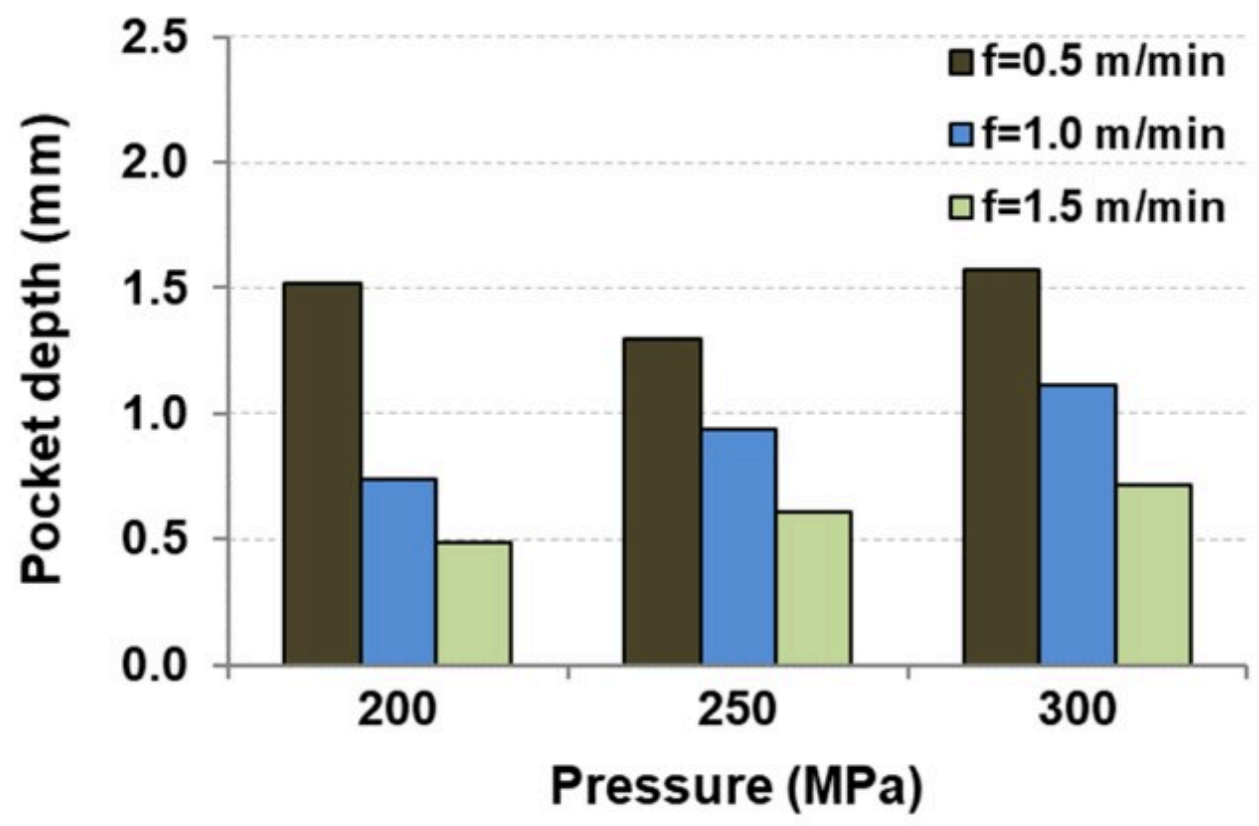

Fig. 4. Effect of pressure and traverse speed on pocket depth. 


\subsection{Residual stress}

The AWJ milling process induces a compressive residual stress state on the machined surfaces in both longitudinal and transverse directions. The longitudinal residual stress varies between $-292 \mathrm{MPa}$ and $-648 \mathrm{MPa}$, the transverse residual stress ranges from $-298 \mathrm{MPa}$ to $-655 \mathrm{MPa}$. It can be noted that the values of the longitudinal and transverse residual stresses are very close; which means that AWJ process does not generate residual stresses in a particular direction unlike conventional machining processes. The small difference between longitudinal and transverse residual stress value is due to the effect of the impingement angle of the waterjet on the surface owing to the machining direction. In addition, it was observed that residual stresses decrease with increasing traverse speed (Fig. 5). This can be explained by the fact that an increase in traverse speed leads to a decrease in exposure time which generates less work-hardening with lower residual stresses. This trend of exposure time on residual stresses was observed in titanium alloy impacted by plain waterjet [29].

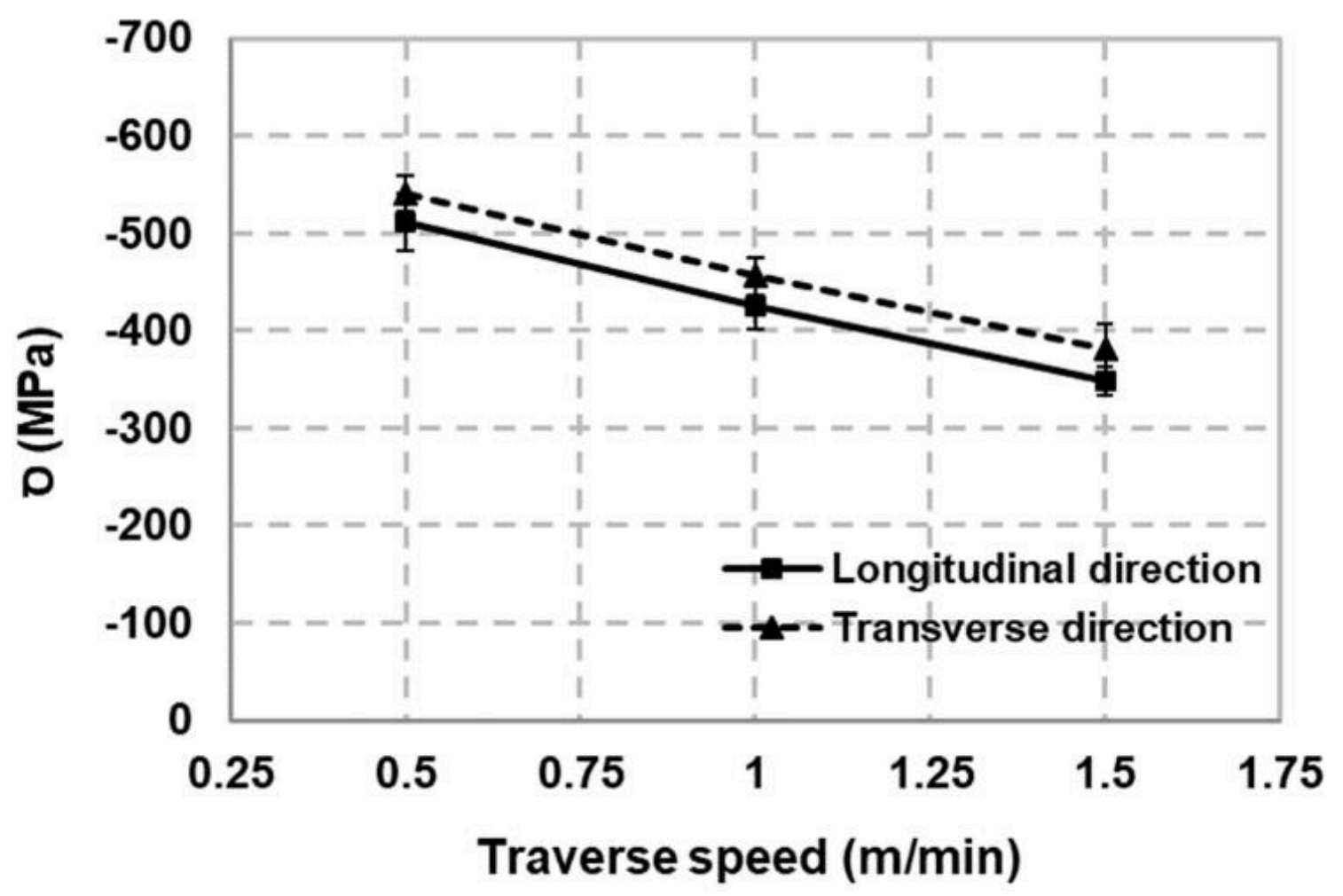

Fig. 5. Effect of traverse speed on residual stresses.

\subsection{Role of abrasive size}

The grit size is also important in AWJ milling. The larger the mesh number, the smaller the abrasive size. No significant effect of abrasive size on surface roughness was observed (Fig. 6). For $\mathrm{P}=300 \mathrm{MPa}$ and mesh \#120, the roughness seems to increase but for the rest of conditions it remains approximately constant. However, in ductile materials [11, 27] was observed that smaller abrasives sizes generate smaller roughness.

Moreover, as the abrasive size increases, the depth of cut decreases (Fig. 6). This can be explained by considering the smaller abrasive sizes (mesh \#120), the larger number of particles impacts per unit area, thus, generating a greater depth of cut. Similar trend was observed when milling SS304 [11]. 


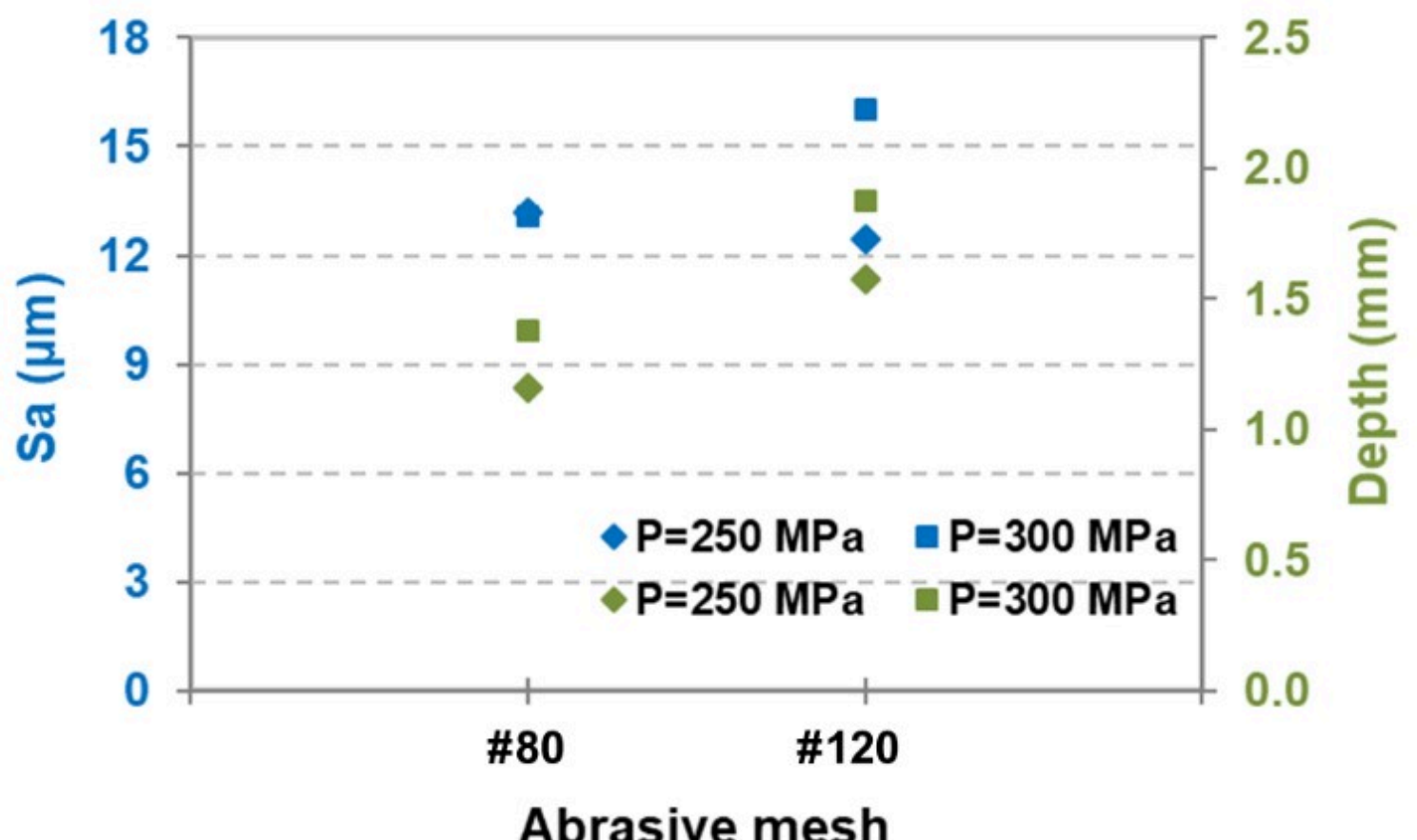

Fig. 6. Influence of abrasive size on surface roughness and pocket depth.

Furthermore, is was noticed that the area of abrasive embedment decreases with an increase in the abrasive mesh (Fig. 7), this implies that the abrasive size is proportional to the embedded fraction, regardless whether whole or fragmented particles embed during milling. This is also reported to occur in [25, 27]; however, it was showed that abrasive embedment is also influenced by the jet impingement angle and the number of passes. 


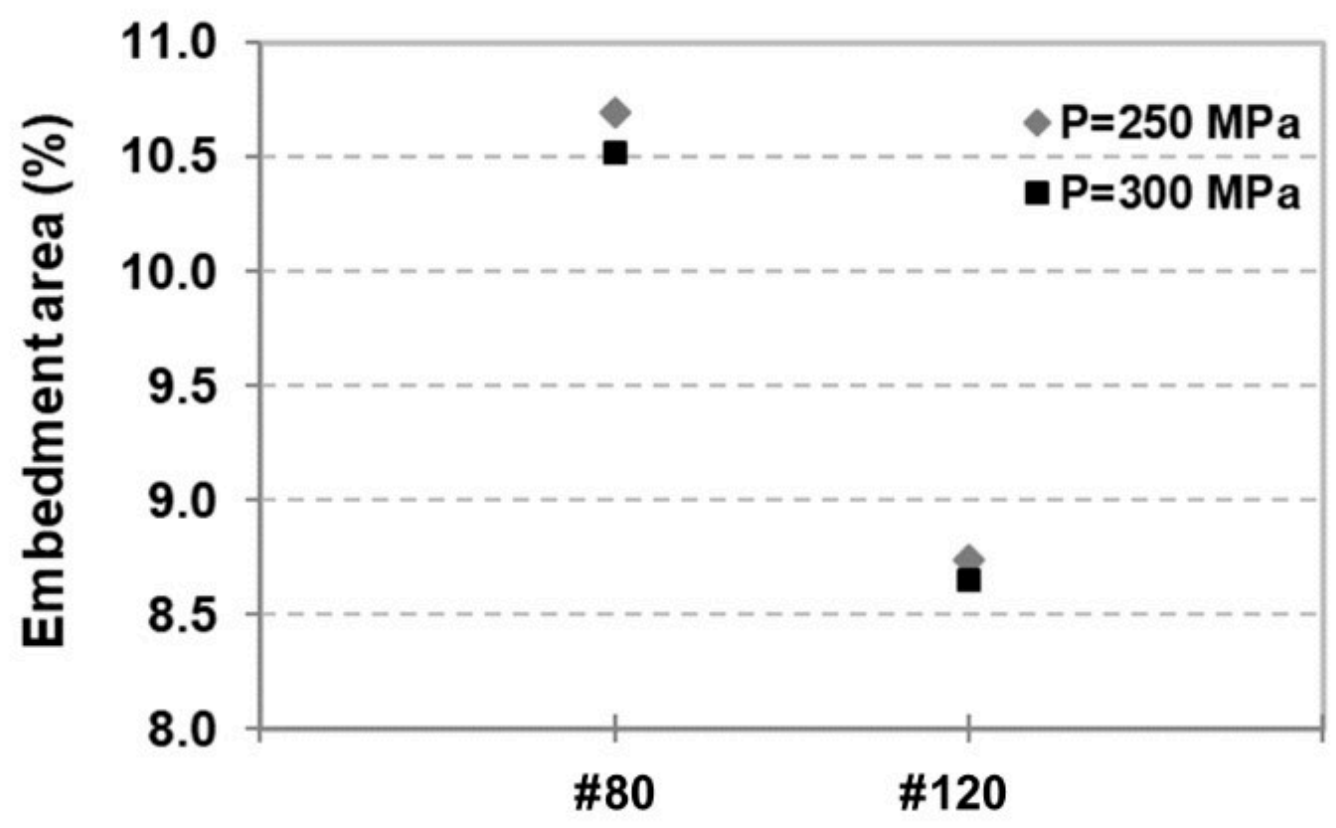

Abrasive mesh

Fig. 7. Influence of grit size and pressure on abrasive embedment area.

As abrasive size is decreased, compressive residual stress increases (Fig. 8). Regardless the pressure, in both longitudinal and transverse directions, a significant increase of $\sim 200 \%$ in residual stresses is observed when abrasive size is decreased. As previously shown in Fig. 6, smaller particles generated deeper pocket depth. Since more particles can remove more material, thus, more plastic deformation is generated, which induce higher residual stresses at surface. 


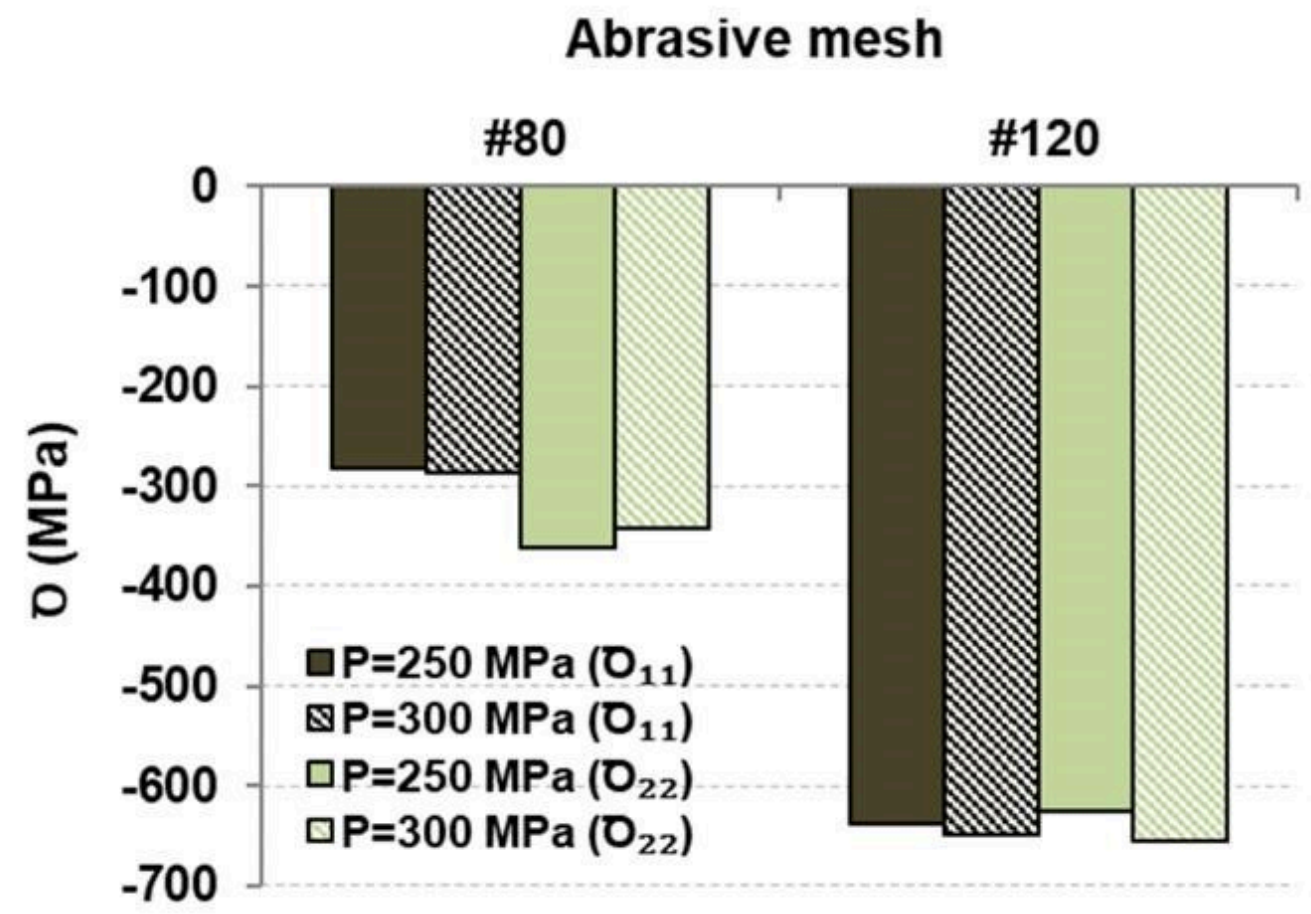

Fig. 8. Influence of abrasive size and pressure on residual stresses.

\section{Conclusions}

The present work investigated experimentally the influence of the AWJ milling parameters, viz. jet pressure, traverse speed and step-over distance on surface roughness, degree of abrasive embedment, pocket depth and residual stress when milling Inconel 718 by AWJ. The results showed that:

- Surface roughness $(\mathrm{Sa}$ ) of the machined surfaces varied between 12 and $25 \mu \mathrm{m}$. As the jet pressure is increased, the surface roughness also increases but decreases with increasing traverse speed.

- All milled surfaces presented embedded abrasive particles which embedment area fraction varied from 7 to $15 \%$. When increasing the pressure, the abrasive embedment decreases, but increases when step-over distance increases.

- Pocket depth ranged between 0.3 to $2.5 \mathrm{~mm}$. An increase in pressure generates an increase in pocket depth, but decreases with increasing traverse speed.

- AWJ milling produced a high compressive residual stress state for all machined specimens. Tool path had no impact in residual stresses. The stress values ranged between $-300 \mathrm{MPa}$ and $-650 \mathrm{MPa}$ in both longitudinal and transverse directions. Increasing traverse speed generates a decrease in residual stress state.

- Smaller abrasive size generates deeper pocket depth, smaller degree of abrasive embedment and higher compressive residual stresses.

- From this study, a model to predict surface characteristics (e.g. depth of cut) in function of machining parameters (pressure, traverse speed, step-over distance) can be considered to future research.

In repair context, AWJ is an interesting alternative for material removal of IN718 instead of conventional process, however, the embedded abrasive particles leads to consider a post-processing. 


\section{Acknowledgements}

The authors are grateful to CONACyT Mexico for supporting this PhD research work. The authors would also like to acknowledge S. Le Roux for assistance with surface topography.

\section{Bibliography}

[1] Yilmaz, O. Gindy, N. Gao, J. A repair and overhaul methodology for aeroengine components. Robotics and ComputerIntegrated Manufacturing, 2010, 26, p. 190201. DOI 10.1016/j.rcim.2009.07.001

[2] Gao, J. Folkes, J. Yilmaz, O. Gindy, N. Investigation of a 3D non-contact measurement based blade repair integration system. Aircraft Engineering and Aerospace Technology, 2005, 77, p. 34-41. DOI 10.1108/00022660510576028

[3] Denkena, B. Boess, V. Nespor, D. Floeter, F. Rust F. Engine blade regeneration: a literature review on common technologies in terms of machining. The International Journal of Advanced Manufacturing Technology, 2015, 81, p. 917-924. DOI 10.1007/s00170-015-7256-2

[4] Wilson, J. M. Piya, C. Shin, Y. C. Zhao, F. Ramani, K. Remanufacturing of turbine blades by laser direct deposition with its energy and environmental impact analysis. Journal of Cleaner Production, 2014, 80, p. 170-178. DOI 10.1016/ j.jclepro.2014.05.084

[5] Gao, J. Chen, X. Yilmaz, O. Gindy, N. An integrated adaptive repair solution for complex aerospace components through geometry reconstruction. The International Journal of Advanced Manufacturing Technology, 2008, 36, p. 1170-1179. DOI 10.1007/s00170-006-0923-6

[6] Bremer, C. Automated repair and overhaul of aero-engine and industrial gas turbine components. Turbo Expo: Power for Land, Sea, and Air, 2005, 4725, p. 841846. DOI 10.1115/GT2005-68193

[7] Bunsch, A. Kowalska, J. Witkowska, M. Influence of die forging parameters on the microstructure and phase composition of Inconel 718 alloy. Archives of Metallurgy and Materials, 2012, 57, p. 929-935. DOI 10.2478/ v10172-012-0102-8

[8] Campbell, Jr. Flake, C. Manufacturing technology for aerospace structural materials. Elsevier Science, 2006

[9] Goutham, U. Hasu, B. S. Chakraverti, G. Kanthababu, M. Experimental investigation of pocket milling on Inconel 825 using abrasive water jet machining. International Journal of Current Engineering and Technology, 2016, 6, p. 295-302.

[10] Alberdi, A. Rivero, A. López de Lacalle, L. Etxeberria, I. Suárez, A. Effect of process parameter on the kerf geometry in abrasive water jet milling. The International Journal of Advanced Manufacturing Technology, 2010, 51, p. 467-480. DOI 10.1007/s00170-010-2662-y

[11] Gupta, T. V. K. Ramkumar, J. Tandon, P. Vyas, N. S. Role of process parameters on pocket milling with Abrasive Water Jet Machining technique. International Journal of Mechanical, Aerospace, Industrial, Mechatronic and Manufacturing Engineering, 2013, 10, p. 348-353. DOI 10.5281/zenodo.1088452

[12] M'Saoubi, R. Larsson, T. Outeiro, J. Guo, Y. Suslov, S. Saldana, C. Chandrasekar, S. Surface integrity analysis of machined Inconel 718 over multiple length scale. CIRP annals, 2012, 61, p. 99-102. DOI 10.1016/j.cirp.2012.03.058

[13] Zhou, J. Bushlya, V. Avdovic, P. Ståhl, J. E. Study of surface quality in high speed turning of Inconel 718 with uncoated and coated CBN tools. The International Journal of Advanced Manufacturing Technology, 2012, 58, p. 141-151. DOI $10.1007 / \mathrm{s} 00170-011-3374-7$ 
Multi-scale characterization of material and surface integrity of Inconel 718 when mill...

[14] Holmberg, J. Berglund, J. Wretland, A. Beno, T. Evaluation of surface integrity after high energy machining with EDM, laser beam machining and abrasive water jet machining of alloy 718. The International Journal of Advanced Manufacturing Technology, 2019, 100, p. 1575-1591. DOI 10.1007/s00170-018-2697-z

[15] Umbrello, D. Investigation of surface integrity in dry machining of Inconel 718. The International Journal of Advanced Manufacturing Technology, 2013, 69, p. 2183-2190. DOI 10.1007/s00170-013-5198-0

[16] Devillez, A. Le Coz, G. Dominiak, S. Dudzinski, D. Dry machining of Inconel 718, workpiece surface integrity. Journal of Materials Processing Technology, 2011, 211, p. 1590-1598. DOI 10.1016/j.jmatprotec.2011.04.011

[17] Zhou, J. M. Bushlya, V. Peng, R. L. Johansson, S. Avdovic, P. Ståhl, J. E. Effects of tool wear on subsurface deformation of nickel-based superalloy. Procedia Engineering, 2011, 19, p. 407-413. DOI 10.1016/j.proeng.2011.11.133

[18] Aspinwall, D. K. Dewes, R. Ng, E. G. Sage, C. Soo, S. L. The influence of cutter orientation and workpiece angle on machinability when high-speed milling Inconel 718 under finishing conditions. International Journal of Machine Tools and Manufacture, 2007, 47, p. 1839-1846. DOI 10.1016/j.ijmachtools.2007.04.007

[19] Momber, A. W. Kovacevic, R. Principles of Abrasive Water Jet Machining. Springer Science \& Business Media, 2012

[20] Bhandarkar, V. Singh, V. Gupta, T. V. K. Experimental analysis and characterization of abrasive water jet machining of Inconel 718. Materials Today: Proceedings, 2020, 23, p. 647-650. DOI 10.1016/j.matpr.2019.04.227

[21] Escobar-Palafox, G. A. Gault, R. S. Ridgway, K. Characterisation of abrasive water-jet process for pocket milling in Inconel 718. 5th CIRP Conference on High Performance Cutting 2012, 2012, p. 404-408. DOI 10.1016/ j.procir.2012.04.001

[22] Ay, M. Çaydaş, U. Hasçalik, A. Effect of traverse speed on abrasive waterjet machining of age hardened Inconel 718 nickel-based superalloy. Materials and Manufacturing Processes, 2010, 25, p. 1160-1165. DOI 10.1080/ 10426914.2010 .502953

[23] Rivero, A. Alberdi, A. Artanza, T. Mendia, L. Lamikiz, A. Surface properties and fatigue failure analysis of alloy 718 surfaces milled by abrasive and plain waterjet. The International Journal of Advanced Manufacturing Technology, 2018, 94, p. 2929-2938. DOI 10.1007/s00170-017-0979-5

[24] Patel, K. J. Quantitative evaluation of abrasive contamination in ductile material during abrasive water jet machining and minimising with a nozzle head oscillation technique. International Journal of Machine Tools and Manufacture, 2004, 44, p. 1125-1132. DOI 10.1016/j.ijmachtools.2003.12.007

[25] Fowler, G. Shipway, P. H. Pashby, I. R. A technical note on grit embedment following abrasive water-jet milling of a titanium alloy. Journal of materials processing technology, 2005, 159, p. 356-368. DOI 10.1016/ j.jmatprotec.2004.05.024

[26] Boud, F. Carpenter, C. Folkes, J. Shipway, P. H. Abrasive waterjet cutting of a titanium alloy: The influence of abrasive morphology and mechanical properties on workpiece grit embedment and cut quality. Journal of Materials Processing Technology, 2010, 210, p. 2197-2205. DOI 10.1016/j.jmatprotec.2010.08.006

[27] Shipway, P. H. Fowler, G. Pashby, I. R. Characteristics of the surface of a titanium alloy following milling with abrasive waterjets. Wear, 2005, 258, p. 123-132. DOI 10.1016/j.wear.2004.04.005

[28] Fowler, G. Pashby, I. R. Shipway, P. H. The effect of particle hardness and shape when abrasive water jet milling titanium alloy Ti6Al4V. Wear, 2009, 266, p. 613620. DOI 10.1016/j.wear.2008.06.013 
[29] Huang, L. Kinnell, P. Shipway, P.H. Removal of heat-formed coating from a titanium alloy using high pressure waterjet: Influence of machining parameters on surface texture and residual stress. Journal of Materials Processing Technology, 2015, 223, p. 129-138. DOI 10.1016/j.jmatprotec.2015.03.053

PDF automatically generated on 2021-05-20 17:54:23

Article url: https://popups.uliege.be/esaform21/index.php?id=4212

published by ULiège Library in Open Access under the terms and conditions of the CC-BY License (https://creativecommons.org/licenses/by/4.0) 